\title{
FESEM, XRD and DRS studies of electrochemically deposited boron doped $\mathrm{ZnO}$ films
}

\author{
Yasemin Caglar, SAliha Ilican*, Mujdat Caglar \\ Department of Physics, Faculty of Science, Anadolu University, 26470 Eskisehir, Turkey
}

\begin{abstract}
In this study, the effect of boron $(\mathrm{B})$ incorporation into zinc oxide $(\mathrm{ZnO})$ has been investigated. The undoped, 2 at. \%. and 4 at.\% $\mathrm{B}$ doped $\mathrm{ZnO}$ films were deposited on p-type silicon ( $\mathrm{Si}$ ) substrates by electrodeposition method using chronoamperometry technique. Electrochemical depositions were performed by applying a constant potentiostatic voltage of $1.1 \mathrm{~V}$ for $180 \mathrm{~min}$ at $90{ }^{\circ} \mathrm{C}$ bath temperature. To analyze the surface morphology, field emission scanning electron microscopy (FESEM) was used and the results revealed that while a small amount of boron resulted in smoother surface, a little more incorporation of boron changed the surface morphology to dandelion-like shaped rods on the whole surface. By using X-ray diffraction (XRD) analysis, the crystal structures of the films were detected and the preferred orientation of the ZnO, which exhibited polycrystalline and hexagonal wurtzite structure, changed with B doping. For the estimation of the optical band gap of obtained films, UV-Vis diffuse reflectance spectra (DRS) of the films were taken at room temperature and these data were applied to the Kubelka-Munk function. The optical band gap of $\mathrm{ZnO}$ narrowed due to incorporation of $\mathrm{B}$, which was confirmed by red-shift.
\end{abstract}

Keywords: B doped ZnO; electrodeposition; rod-shaped morphology; Kubelka-Munk

\section{Introduction}

Among different metal oxides, $\mathrm{ZnO}$ is one of the most remarkable for many optoelectronic and optical applications due to its wide direct optical band gap (around $3.37 \mathrm{eV}$ ), high exciton binding energy (60 meV, compared to $25 \mathrm{meV}$ of $\mathrm{GaN}$ ), high transmittance, low electrical resistivity and high resistance to radiation damage. Particularly, it is desirable and favorite material in solar cells [1], heterojunction diodes [2-4], thin film transistor [5-7] and sensor [8, 9] applications. That is, it is a key technological material. Additionally, as it can be deposited in different nanostructures, such as nanowires, nanorods, nanofibers, nanorings, nanobelts and nanospheres, it can be said that $\mathrm{ZnO}$ has the richest nanostructures family among all metal oxides. Of course, the deposition of these nanostructures at low-cost and by simple methods would ensure their more intensive use in industry. To improve many of physical properties of $\mathrm{ZnO}$, generally, some suitable trivalent ions, such as $\mathrm{Al}^{3+}, \mathrm{In}^{3+}$, and $\mathrm{B}^{3+}$, are used. Among them,

*E-mail: silican@ anadolu.edu.tr the usage of B doping is less common than of other elements. For deposition of $\mathrm{B}$ doped $\mathrm{ZnO}$, inexpensive and uncomplicated methods, such as spray pyrolysis [10, 11], sol gel [12-14] and electrodeposition, [15-18] can be applied. Chronoamperometry, one of the electrodeposition techniques, is widely used for film deposition because it is simple and economical. There are a few works which have been reported in the available literature about $\mathrm{B}$ doped $\mathrm{ZnO}$ growth by the same method. In one of these works, Izaki et al. [15] reported that undoped and $\mathrm{B}$ doped $(0.005 \mathrm{~mol} / \mathrm{L}$, $0.03 \mathrm{~mol} / \mathrm{L}$ and $0.1 \mathrm{~mol} / \mathrm{L}$ dimethylamineborane (DMAB) solutions) $\mathrm{ZnO}$ films were deposited chemically onto nonconductive substrates and their crystalline structures exhibited (llllll $\left.0 \begin{array}{lll}0 & 2\end{array}\right)$ preferred orientation increasing with increasing B content. In the same work, an improvement in the transparency in the visible region and electrical resistivity with an increase of B content was also reported. In the report of Ishizaki et al. [16], the effects of cathodic potential (between $-0.8 \mathrm{~V}$ and $1.2 \mathrm{~V}$ ) during the electrochemical growth were reported. According to this report, boron doping increasing from $0.41 \%$ to $1.1 \%$, in this potential range, caused a decrease 
in electrical resistivity. In the study published by Calnan et al. [17], B doped $\mathrm{ZnO}$ films were prepared by using zinc nitrate and boric acid solutions (1 at.\% to 20 at.\% $\mathrm{B}$ ratios) and SEM images presented the existence of grains with hexagonal faces for low B contents and the clustering of these grains for 20 at. $\%$ B content. Tsin et al. [18] revealed that an increase in boric acid concentration changed the size of the columns from $180 \mathrm{~nm}$ to $600 \mathrm{~nm}$ and PL emission peak of the films shifted to higher energy.

Although many researchers have studied the deposition of $\mathrm{B}$ doped $\mathrm{ZnO}$ films by using different solution methods, dandelion-like structure B doped $\mathrm{ZnO}$ films obtained using electrodeposition method have not been studied yet. The difference of this study from the above-mentioned previous works is the growth of $\mathrm{B}$ doped $\mathrm{ZnO}$ films having the dandelion-like rods structure by electrodeposition method and investigation of the effect of incorporated boron on the structural, morphological and optical properties of these films.

\section{Experimental}

In the electrodeposition process, zinc nitrate hexahydrate $\left(\mathrm{Zn}\left(\mathrm{NO}_{3}\right)_{2} \cdot 6 \mathrm{H}_{2} \mathrm{O}, \geqslant 99.00 \%\right.$ purity), hexamethylenetetramine $\left(\mathrm{C}_{6} \mathrm{H}_{12} \mathrm{~N}_{4}, \geqslant 99.50 \%\right.$ purity) and boric acid $\left(\mathrm{H}_{3} \mathrm{BO}_{3}, 99.99 \%\right.$ purity), purchased from Sigma-Aldrich Company, were used. As a substrate, p-Si (B doped, (l 100 ) oriented, $525 \mu \mathrm{m}$ thick, $\mathrm{R}=1 \Omega$ to $10 \Omega$ ) wafers that were purchased from Monto Silicon Technologies Inc. were used.

Both undoped and $\mathrm{B}$ doped $\mathrm{ZnO}$ films were electrochemically deposited on the $\mathrm{p}$-Si wafers from aqueous solution, using chronoamperometry method. The aqueous solution was composed of $\left(5 \times 10^{-2} \mathrm{M}\right) \mathrm{Zn}\left(\mathrm{NO}_{3}\right)_{2} \cdot 6 \mathrm{H}_{2} \mathrm{O}$ and $\left(5 \times 10^{-2} \mathrm{M}\right)$ $\mathrm{C}_{6} \mathrm{H}_{12} \mathrm{~N}_{4} .2 \%$ and $4 \%$ atomic ratios of $\mathrm{H}_{3} \mathrm{BO}_{3}$ were used as a dopant source. During the electrochemical deposition, the temperature was maintained at $90{ }^{\circ} \mathrm{C}$. A three-electrode system was used with $\mathrm{p}$-Si as working electrode, platinum $(\mathrm{Pt})$ wire as a counter electrode and a potassium chloride saturated silver/silver chloride $(\mathrm{Ag} / \mathrm{AgCl}, 3 \mathrm{M}$ $\mathrm{KCl}$ saturated) as a reference electrode for all electrochemical experiments. Before each electrochemical deposition, Si wafers were ultrasonically cleaned for $10 \mathrm{~min}$ in acetone and DI water. After this process, the substrates were dried with pure nitrogen $\left(\mathrm{N}_{2}\right)$ gas. Then, they were etched in argon (Ar) plasma ambient for $1 \mathrm{~min}$. The deposition was performed at $-1.1 \mathrm{~V}$ (versus $\mathrm{Ag} / \mathrm{AgCl}$ ) for $180 \mathrm{~min}$. Electrodeposited $\mathrm{ZnO}$ films: undoped, $2 \%$ and $4 \%$ B doped were indexed as BZ0, BZ2, and BZ4, respectively.

GAMRY 3000 Potentiostat/Galvanostat/ZRA System was used to deposit $\mathrm{ZnO}$ films electrochemically. In the process of structural, morphological and optical characterizations carried out at room temperature, BRUKER D2 Phaser Xray diffractometer (XRD), ZEISS Ultra Plus field emission scanning electron microscope (FE-SEM) and SHIMADZU 2450 spectrophotometer with an integrating sphere attachment were used. Measuring interval of XRD measurements $(\mathrm{CuK} \alpha$; $\lambda=0.15418 \mathrm{~nm}$ ) was $2 \theta=30^{\circ}$ to $60^{\circ}$, scan speed was $0.02 \%$ at a divergent slit of $0.5 \mathrm{~mm}$ width.

\section{Results and discussion}

\subsection{Morphological properties of elec- trodeposited undoped and $\mathrm{B}$ doped $\mathrm{ZnO}$ films}

The surface morphology of electrodeposited undoped and $\mathrm{B}$ doped $\mathrm{ZnO}$ films was investigated by SEM analysis. Fig. 1 shows that boron incorporation into the $\mathrm{ZnO}$ lattice caused important changes in both particle size and shapes. At the same time, an improvement of the surface depending on the boron incorporation is seen in these images. As seen in Fig. 1a, undoped $\mathrm{ZnO}$ surface has rough surface where numerous aggregations are visible. At small boron incorporation, the surface is smoother and the density of hexagonal rods also increases. When the boron incorporation is slightly increased, the surface morphology changes completely, that is, the hexagonal rods become thinner by one-third and dandelion-like rods emerge on the whole surface. 


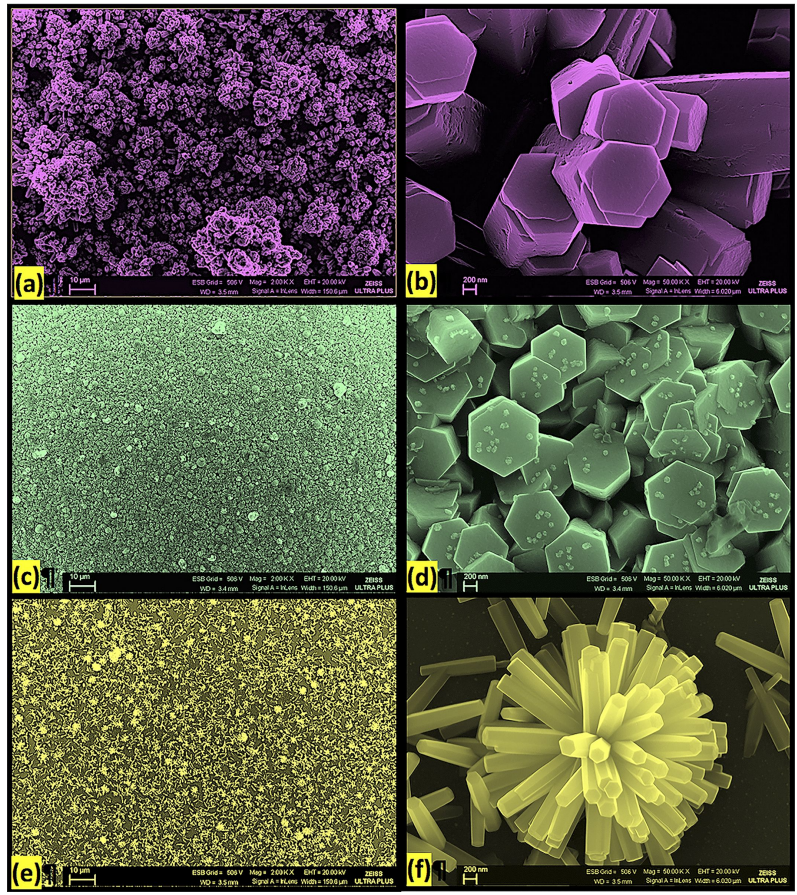

Fig. 1. SEM images of the BZ0, BZ2 and BZ4 films at $\times 200000(\mathrm{a}, \mathrm{c}, \mathrm{e})$ and $\times 5000000(\mathrm{~b}, \mathrm{~d}, \mathrm{f})$ magnifications, respectively.

\subsection{Structural properties of electrode- posited undoped and $\mathrm{B}$ doped $\mathrm{ZnO}$ films}

XRD method was used for determination of crystallinity and the preferred orientation of undoped and $\mathrm{B}$ doped $\mathrm{ZnO}$ films. Fig. 2 shows diffraction patterns of the obtained films. In these patterns, the diffraction peaks belonging to $\mathrm{ZnO}$ hexagonal wurtzite structure (JCPDS Card No. 361451 , zincite phase) can be clearly seen. The absence of other impurity phases in these patterns indicates that $\mathrm{B}$ ions successfully occupy the lattice sites rather than interstitial ones. The $2 \theta$ values in

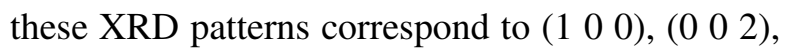
$\left(\begin{array}{lll}1 & 0 & 1\end{array}\right),\left(\begin{array}{lll}1 & 0 & 2\end{array}\right)$ and $\left(\begin{array}{lll}1 & 1 & 0\end{array}\right)$ diffraction planes at JCPDS Card of $\mathrm{ZnO}$. The effect of boron incorporation on crystallinity of the $\mathrm{ZnO}$ films is seen also from Fig. 2. B doping has not caused any change in the structure and the absence of impurity phases in all the films suggests that most of B ions occupy the sites within the $\mathrm{ZnO}$ lattice. The diffraction peaks present a slight shift to lower angles with B doping.
This shift is attributed to the substitution of $\mathrm{Zn}$ by B ions, which may suggest the successful doping procedure.

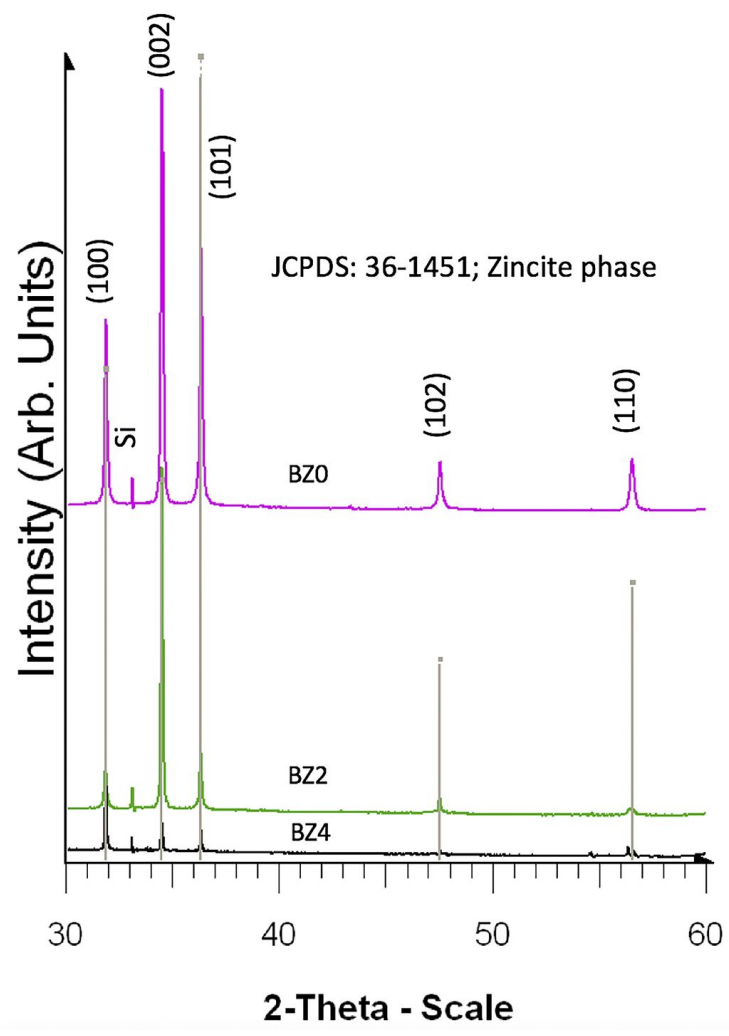

Fig. 2. XRD patterns of the undoped and $\mathrm{B}$ doped $\mathrm{ZnO}$ films.

For all deposited films, the angle of diffraction $2 \theta$ and lattice spacing $d$ of the phases specified along with the related ( $\mathrm{h} \mathrm{k} \mathrm{l}$ ) planes are given in Table 1. For determination of the preferential orientation of the films, texture coefficient TC(h k l) relation defined below was used [19]:

$$
T C(h k l)=\frac{I(h k l) / I_{o}(h k l)}{N^{-1} \sum_{n} I(h k l) / I_{o}(h k l)}
$$

where $\mathrm{I}(\mathrm{h} \mathrm{k} \mathrm{l})$ is the observed intensity of a plane (h k l), $\mathrm{I}_{\mathrm{o}}(\mathrm{h} \mathrm{k} \mathrm{l}$ ) is the standard intensity of the plane (h $\mathrm{k}$ l) taken from the JCPDS data and $\mathrm{N}$ is the number of diffraction peaks. A result of evaluation of $\mathrm{TC}(\mathrm{h} \mathrm{k} \mathrm{l})$, whose value can be close to unity or larger than unity, means that the film has randomly or preferentially oriented (h k l) planes, respectively. The predominant plane orientation of the film has high texture coefficient value. 
Table 1. Structural parameters of the undoped and B doped $\mathrm{ZnO}$ films.

\begin{tabular}{|c|c|c|c|c|}
\hline Film code & $(\mathrm{h} \mathrm{k} \mathrm{l)}$ & $2 \theta\left[{ }^{\circ}\right]$ & $\mathrm{d}[\AA]$ & $\mathrm{TC}$ \\
\hline \multirow{5}{*}{ BZ0 } & $\left(\begin{array}{lll}1 & 0 & 0\end{array}\right)$ & 31.802 & 2.812 & 0.75 \\
\hline & $\left(\begin{array}{lll}0 & 0 & 2\end{array}\right)$ & 34.446 & 2.602 & 1.39 \\
\hline & $\left(\begin{array}{lll}1 & 0 & 1\end{array}\right)$ & 36.270 & 2.475 & 0.49 \\
\hline & $\left(\begin{array}{lll}1 & 0 & 2\end{array}\right)$ & 47.548 & 1.911 & 1.37 \\
\hline & $\left(\begin{array}{lll}1 & 1 & 0\end{array}\right)$ & 56.592 & 1.625 & 1.00 \\
\hline \multirow{5}{*}{ BZ2 } & $\left(\begin{array}{lll}1 & 0 & 0\end{array}\right)$ & 31.787 & 2.813 & 0.51 \\
\hline & $\left(\begin{array}{lll}0 & 0 & 2\end{array}\right)$ & 34.427 & 2.603 & 2.78 \\
\hline & $\left(\begin{array}{lll}1 & 0 & 1\end{array}\right)$ & 36.250 & 2.476 & 0.33 \\
\hline & $\left(\begin{array}{lll}1 & 0 & 2\end{array}\right)$ & 47.533 & 1.911 & 0.86 \\
\hline & $\left(\begin{array}{lll}1 & 1 & 0\end{array}\right)$ & 56.543 & 1.626 & 0.52 \\
\hline \multirow{5}{*}{ BZ4 } & $\left(\begin{array}{lll}1 & 0 & 0\end{array}\right)$ & 31.795 & 2.812 & 2.12 \\
\hline & $\left(\begin{array}{lll}0 & 0 & 2\end{array}\right)$ & 34.415 & 2.604 & 1.42 \\
\hline & $\left(\begin{array}{lll}1 & 0 & 1\end{array}\right)$ & 36.256 & 2.476 & 0.48 \\
\hline & $\left(\begin{array}{lll}1 & 0 & 2\end{array}\right)$ & 47.495 & 1.913 & 0.64 \\
\hline & $\left(\begin{array}{lll}1 & 1 & 0\end{array}\right)$ & 56.499 & 1.627 & 0.34 \\
\hline
\end{tabular}

The TC(h k l) values calculated from the diffraction peaks are given in Table 1. It is seen that the highest TC values have been obtained for $\left(\begin{array}{lll}0 & 0 & 2\end{array}\right)$ plane for $\mathrm{BZ0}$ and $\mathrm{BZ2}$ films. In contrast, the highest $\mathrm{TC}$ value for BZ4 belongs to (1 $\left.\begin{array}{lll}1 & 0\end{array}\right)$ plane, which means that the preferred orientation has changed. A decrease of dominance of (llll $\left.\begin{array}{lll}0 & 2\end{array}\right)$ peak value with incorporation of small amount of $\mathrm{B}$ was also observed in previously reported study [20]. The change in observed preferred orientation for BZ4 supports the change in surface morphology obtained from SEM.

To calculate the lattice parameters (a and c) of the films, the following equation was used [21]:

$$
\frac{1}{d^{2}}=\frac{4}{3}\left(\frac{h^{2}+h k+k^{2}}{a^{2}}\right)+\frac{l^{2}}{c^{2}}
$$

The calculated values are presented in Table 2. As seen in Table 2, the lattice parameters of the films increase with increasing $\mathrm{B}$ content, which results from the fact that $\mathrm{B}^{3+}(0.23 \AA)$ and $\mathrm{Zn}^{2+}(0.74 \AA)$ have very different ionic radii [22]. Therefore, this large difference, as a result of the incorporation of greater amounts of B dopant into $\mathrm{ZnO}$ films, will cause both lattice distortion and tendency to create lattice defects and nucleation centers [23, 24].

Table 2. Lattice constants and crystal lattice distortion degree of the undoped and $\mathrm{B}$ doped $\mathrm{ZnO}$ films.

\begin{tabular}{lccc}
\hline Film code & $\mathrm{a}[\AA]$ & $\mathrm{c}[\AA]$ & $\mathrm{R}$ \\
\hline \hline BZ0 & 3.24656 & 5.20310 & 1.01893 \\
BZ2 & 3.24801 & 5.20590 & 1.01884 \\
BZ4 & 3.24718 & 5.20766 & 1.01824 \\
\hline
\end{tabular}

The crystal lattice distortion degree $\mathrm{R}$ can be determined by the following equation [25]:

$$
R=\frac{\left[2 a\left(\frac{2}{3}\right)^{1 / 2}\right]}{c}
$$

The $\mathrm{R}$ values of the films are presented in Table 2. As seen in this Table, the crystal lattice distortion degree increases with increasing $\mathrm{B}$ content. Probably, the substitution of $\mathrm{Zn}^{2+}$ by $\mathrm{B}^{3+}$ in the lattice causes the distortion of the lattice of $\mathrm{ZnO}$, resulting from the large difference between the two ions.

\subsection{Optical properties of electrodeposited undoped and $\mathrm{B}$ doped $\mathrm{ZnO}$ films}

The Kubelka-Munk model is one of the most commonly used methods to estimate the optical band gap of powder samples or opaque films. In this model, the data of diffuse reflectance $\mathrm{R}$ spectrum are used. For this purpose, R spectra of all the obtained films were measured at room temperature by taking a $\mathrm{BaSO}_{4}$ powder as a reference (Fig. 3). The average $\mathrm{R}$ values of these films changed from $27 \%$ to $47 \%$ with increasing B content.

The optical band gap $\left(E_{g}\right)$ is determined from the following relation [26]:

$$
\left(\frac{F(R) h v}{t}\right)^{2}=A\left(h v-E_{g}\right)
$$

where $F(R), h v, t$ and $A$ are Kubelka-Munk function $\left(F(R)=(1-R)^{2} / 2 R\right)$, the photon energy, the thickness of the film and a constant, respectively. The $E_{g}$ values of the obtained films estimated from 


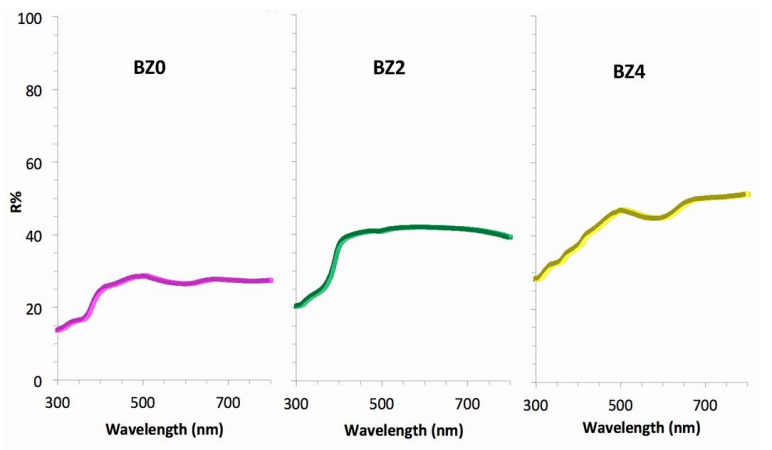

Fig. 3. The diffuse reflectance spectra of the undoped and $\mathrm{B}$ doped $\mathrm{ZnO}$ films.

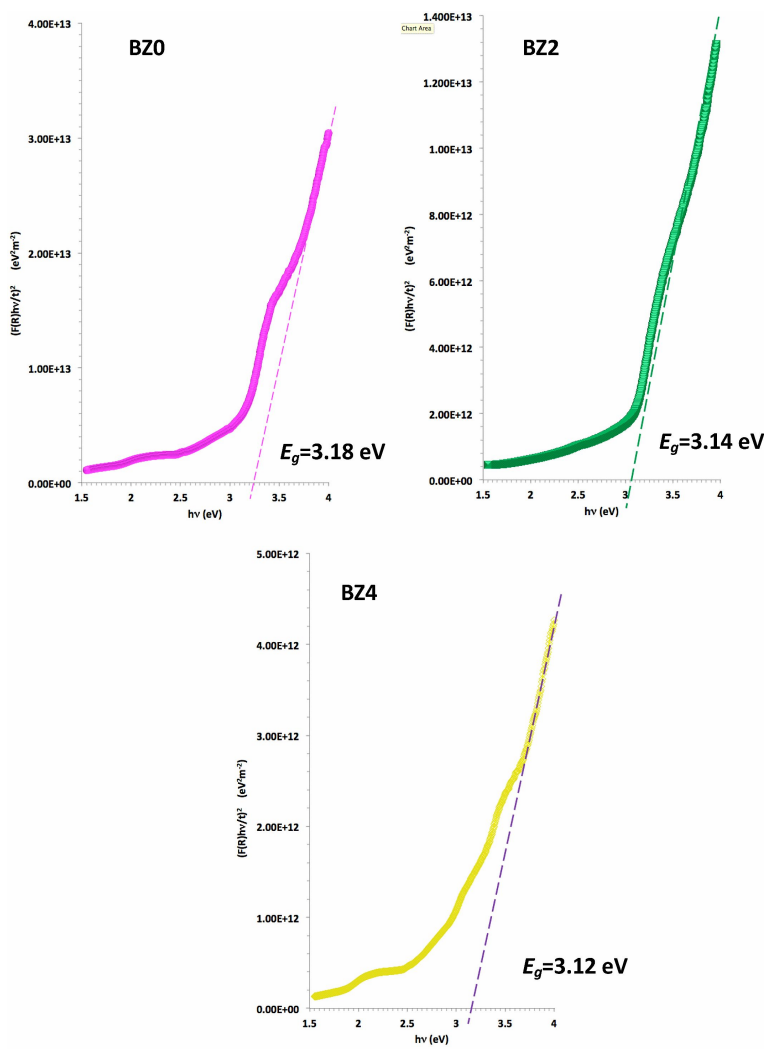

Fig. 4. Kubelka-Munk plots of the undoped and B doped $\mathrm{ZnO}$ films.

the variation of the $(\mathrm{F}(\mathrm{R}) \mathrm{h} v / \mathrm{t})^{2}$ with $\mathrm{h} v$ are shown in Fig. 4. As it can be seen, the $\mathrm{E}_{\mathrm{g}}$ values have been obtained by the extrapolation of the linear portion of the curves. The extrapolated $E_{g}$ values decrease slightly with the incorporation of $\mathrm{B}$. This systematic decrease in the optical band gap is found to be $60 \mathrm{meV}$ and probably, is due to existence of $\mathrm{B}$ impurities. Also, in these graphs, more than one linear region is shown. As mentioned before, in the Kubelka-Munk model, the direct diffuse reflection results have been used and the incorporation of boron has changed the surface morphology, as the existence of more than one linear region can be attributed to varying surface properties.

In summary, the absorption edge of the obtained films is observed to shift towards the higher wavelength region (red shift). The so called shrinkage effect points out a decrease in $E_{g}$ values of the films with increasing B content.

\section{Conclusions}

Structural, morphological and optical properties of undoped and $\mathrm{B}$ doped $\mathrm{ZnO}$ films deposited by electrodeposition were investigated. According to $\mathrm{XRD}$ results, the $4 \% \mathrm{~B}$ doped $\mathrm{ZnO}$ film exhibited different preferred orientation, and different surface morphology in the form of dandelion-like rods. At the same time, the measurements carried out for estimating the band gap showed an increase in the band gap caused by an increase in boron incorporation. Based on these results, we can say that boron incorporation caused significant changes in the structural, morphological and optical properties of $\mathrm{ZnO}$.

\section{Acknowledgements}

This work was supported by the Anadolu University Commission of Scientific Research Projects under the Grants No. 1207F118 and 1305F082.

\section{References}

[1] Peksu E., KaraAgac H., J. Nanomater, 2015 (2015), 16012.

[2] Caglar M., Gorgun K., J. Nanoelectron. Optoelectron., 11 (2016), 769.

[3] Xiong C., YaO R., Optik, 126 (2015), 1951.

[4] Caglar Y., Arslan A., Ilican S., Hur E., AKSOY S., CAglar M., J. Alloy. Compd., 574 (2013), 104.

[5] RuZgar S., Aksoy S., J. Mater. Electron. Devices, 1 (2015), 38.

[6] Caglar Y., Caglar M., Ilican S., AKsoy S., Yakuphanoglu F., J. Alloy. Compd., 621 (2015), 189.

[7] Ye W., Deng J., Wang X., Cui L., Appl. Surf. Sci., 390 (2016), 831.

[8] Maziarz W., Rydosz A., Wysocka K., PISARKIEWICZ T., Mater. Sci.-Poland, 32 (2014), 176. 
[9] Ates T., Tatar C., Yakuphanoglu F., Sensor. Actuat. A-Phys., 190 (2013) 153.

[10] Kerli S., Alver U., TAnriverdi A., Avar B., Crystallogr. Rep., 60 (2015), 946.

[11] Yu C.C., Hsu Y.T., LeE S.Y., LAN W.H., KuO H.H., Shin M.C., Feng D.J.Y., Huang K.F., Jpn. J. Appl. Phys., 52 (2013), 1.

[12] Gandla S., Gollu S. R., Sharma R., Sarangi V., Gupta D., Appl. Phys. Lett., 107 (2015), 152102.

[13] Caglar M., IllCaN S., CAglar Y., Yakuphanoglu F., J. Alloy. Compd., 509 (2011), 3177.

[14] Ilican S., Yakuphanoglu F., Caglar M., Caglar Y., J. Alloy. Compd., 509 (2011), 5290.

[15] IZAKi M., Katayama J., J. Electrochem. Soc., 147 (2000), 210.

[16] IshizaKi H., Imaizumi M., Matsuda S., IZAKI M., ITo T., Thin Solid Films, 411 (2002), 65.

[17] Calnan S., Riedel W., Gledhill S., StanNOWSKI B., STEINER L.M.C., SCHLATMANN R., Thin Solid Films, 594 (2015), 215.
[18] Tsin F., Thomere A., Bris A.L., Collin S., LiNCot D., Rousset J., ACS Appl. Mater. Inter., 8 (2016), 12298.

[19] Barret C.S., MassalsKi T.B., Structure of Metals, Pergamon Press, Oxford, 1980.

[20] Pawar B.N., Jadkar S.R., Takwale M.G., J. Phys. Chem. Solids, 66 (2005), 1779.

[21] Cullity B.D., Stock S.R., Elements of X-ray Diffraction, $2^{\text {nd }}$ Ed., Prentice-Hall, Inc., New Jersey, 2001.

[22] Mao C., Fang L., Zhang H., Li W., Wu F., Qin G., RuAn H., Kong C., J. Alloy. Compd., 676 (2016), 135.

[23] Senol S.D., Ozturk O., Terzioglu C., Ceram. Int., 41 (2015), 11194.

[24] Tsay C.-Y., Hsu W.-T., Ceram. Int., 39 (2013), 7425.

[25] Gaudon M., Toulemonde O., Demourgues A., Inorg. Chem., 46 (2007), 10996.

[26] Murphy A.B., Sol. Energ. Mat. Sol. C., 91 (2007), 1326.

Received 2017-03-28 Accepted 2017-10-08 